\title{
Triple therapy versus single and dual long-acting bronchodilator therapy in COPD: a systematic review and meta-analysis
}

\author{
Mario Cazzola ${ }^{1}$, Paola Rogliani ${ }^{1}$, Luigino Calzetta ${ }^{1}$ and Maria Gabriella Matera ${ }^{2}$ \\ Affiliations: "Unit of Respiratory Medicine, Dept of Experimental Medicine, University of Rome "Tor Vergata", \\ Rome, Italy. "Unit of Pharmacology, Dept of Experimental Medicine, University of Campania "Luigi Vanvitelli", \\ Naples, Italy. \\ Correspondence: Luigino Calzetta, Dept of Experimental Medicine, University of Rome "Tor Vergata", Via \\ Montpellier 1, 00133, Rome, Italy. E-mail: luigino.calzettaduniroma2.it
}

@ERSpublications

Triple therapy is more effective than single and dual bronchodilator therapy in reducing risk of acute exacerbation of COPD, mainly in eosinophilic patients http://ow.ly/9Jp630mcXJD

Cite this article as: Cazzola M, Rogliani P, Calzetta L, et al. Triple therapy versus single and dual longacting bronchodilator therapy in COPD: a systematic review and meta-analysis. Eur Respir J 2018; 52: 1801586 [https://doi.org/10.1183/13993003.01586-2018].

ABSTRACT We performed a meta-analysis to compare the impact of triple combination therapy with inhaled corticosteroids (ICS), long-acting $\beta_{2}$-agonists (LABAs) and long-acting muscarinic receptor antagonists (LAMAs) versus LABA/LAMA combination therapy or single long-acting bronchodilator therapy in chronic obstructive pulmonary disease. The ICS/LABA/LAMA combination reduced the risk of exacerbation (relative risk $0.70,95 \%$ CI $0.53-0.94$ ) and improved trough forced expiratory volume in $1 \mathrm{~s}$ (mean difference in $\mathrm{mL}+37.94$, 95\% CI 18.83-53.89) versus LABA/LAMA combination therapy. The protective effect of triple combination therapy versus LABA/LAMA combination therapy against risk of exacerbation was greater in patients with blood eosinophil counts $\geqslant 300$ cells $\mu \mathrm{L}^{-1}$ (relative risk $0.57,95 \%$ CI 0.48-0.68). While $\sim 38$ patients had to be treated for 1 year with ICS/LABA/LAMA combination therapy to prevent one exacerbation compared to LABA/LAMA combination therapy, the number needed to treat (NNT) was $\sim 21$ when compared to single long-acting bronchodilator therapy. The person-based NNT per year of ICS/LABA/LAMA combination therapy versus LABA/LAMA combination therapy was significantly $(\mathrm{p}<0.05)$ lower in patients with eosinophil counts $\geqslant 300$ cells $\mu \mathrm{L}^{-1}$ (NNT value: 8.58$)$ than in those with counts $<300$ cells $\mu \mathrm{L}^{-1}$ (NNT value: 46.28 ). The risk of pneumonia did not differ between ICS/ LABA/LAMA combination therapy and its comparators. The number needed to harm was $\sim 195$. This meta-analysis suggests that patients on single long-acting bronchodilator therapy or LABA/LAMA combination therapy, who still have exacerbations and have blood eosinophil counts $\geqslant 300$ cells $\mu \mathrm{L}^{-1}$, could benefit from ICS/LABA/LAMA combination therapy. 


\section{Introduction}

Although triple combination therapy with inhaled corticosteroids (ICS), long-acting $\beta_{2}$-agonists (LABAs) and long-acting muscarinic receptor antagonists (LAMAs) is recommended for the most severe chronic obstructive pulmonary disease (COPD) patients [1-6], a majority of the patients who receive an ICS/LABA/LAMA combination may only have mild or moderate disease [7-9].

Since triple combination therapy should be prescribed to patients with COPD only when necessary and in concordance with treatment recommendations [9], and because there is no conclusive evidence on the superiority of triple therapy over other therapeutic options (particularly in patients at low risk of exacerbations), we performed a systematic review and a meta-analysis to determine the effect of ICS/ LABA/LAMA combination therapy on the risk of exacerbation and other relevant outcomes in patients with COPD.

\section{Methods}

Search strategy

This meta-analysis has been registered in the PROSPERO database (www.crd.york.ac.uk/prospero/; registration number CRD42018095300) and performed in agreement with the Preferred Reporting Items for Systematic Reviews and Meta-Analyses Protocols (PRISMA-P) [10]. The PRISMA flow diagram is reported in supplementary figure $\mathrm{S} 1$. This quantitative synthesis satisfied all the recommended items reported by the PRISMA-P checklist (supplementary table S1) [10].

Two reviewers performed a comprehensive literature search for randomised controlled trials (RCTs) evaluating the effects of ICS/LABA/LAMA combination therapy in COPD patients. The Patient problem, Intervention, Comparison, and Outcome (PICO) framework was used to develop the literature search strategy, as previously described [11]. Namely, the patient problem included "subject affected by COPD", the intervention regarded the "administration of ICS/LABA/LAMA combination therapy", the comparison was performed with regard to "single long-acting bronchodilator therapy and dual bronchodilator therapy" and the outcomes were the "risk of acute exacerbation of COPD (AECOPD), lung function, quality of life (QoL) and safety profile”.

The term "triple AND combination AND COPD" was searched in the Cochrane Central Register of Controlled Trials (CENTRAL), the MEDLINE, Embase, Scopus, Google Scholar, Web of Science, ClinicalTrials.gov databases and the EU Clinical Trials Register, in order to provide for relevant studies available up to May 30, 2018. No language restrictions were applied.

Citations of previously published meta-analyses and relevant reviews were examined to identify further pertinent studies, if any [12-14].

Literature search results were uploaded to Eppi-Reviewer 4 (EPPI-Centre Software, London, UK), a web-based software programme for managing and analysing data in literature reviews that facilitates collaboration among reviewers during the study selection process.

\section{Study selection}

Published RCTs involving COPD patients that directly compared fixed or free ICS/LABA/LAMA combination therapy with fixed or free LABA/LAMA combination therapy and single long-acting bronchodilator therapy were included in this meta-analysis.

Two reviewers independently checked the relevant studies identified from literature searches obtained from the already mentioned databases. The studies were selected in agreement with the above-mentioned criteria and any difference in opinion about eligibility was resolved by consensus.

\section{Data analysis}

A network meta-analysis was performed to determine the effects of ICS/LABA/LAMA combination therapy on the primary end-points, compared with LABA/LAMA combination therapy or single longacting bronchodilator therapy. The network meta-analysis permitted the ranking by efficacy of ICS/LABA/ LAMA combination therapy, LABA/LAMA combination therapy and single long-acting bronchodilator therapy with regard to the primary end-points. A pairwise meta-analysis was also performed to confirm results obtained from the network meta-analysis and to investigate secondary end-points. Results of the pairwise meta-analysis were used to assess heterogeneity and bias via funnel plot and Egger's test, and to quantify the relative weights of the studies included in this quantitative synthesis.

Results of the network meta-analysis are expressed as relative effect and 95\% credible interval (95\% CrI). Results of the pairwise meta-analysis are expressed as relative risk or mean difference and $95 \%$ confidence interval (95\% CI). Since data were selected from a series of studies performed independently, a common 
effect size could not be assumed; thus a random-effects model was used to estimate the 95\% CI for the mean distribution of drugs' effect on the investigated variables [15]. Detailed methods on the network meta-analysis and surface under the cumulative ranking curve (SUCRA) analysis are reported in the supplementary data file.

The analysis of the number needed to treat (NNT) and number needed to harm (NNH) was performed on primary end-points. NNT and NNH are the reciprocal of the absolute risk reduction or increase, respectively, and are associated with an intervention over a fixed period of time [16-18]. The values of NNT and NNH are reported in this study as person-based and are calculated by analysing the KaplanMeier curves or by using the raw data provided in the primary publications, as previously described [ 19 , 20]. The relative weight of each study resulting from the pairwise meta-analysis was used to calculate the weighted average (WA) rate of the investigated arms (namely the ICS/LABA/LAMA combination arm, the LABA/LAMA combination arm and the single long-acting bronchodilator arm) and to correctly provide NNT and NNH values.

Subset analyses were focused on severe AECOPDs and blood eosinophil counts, and sensitivity analyses were performed to identify the studies that introduced heterogeneity into the findings. Meta-regression analysis was performed to examine the source of heterogeneity between-studies $\left(\mathrm{I}^{2}\right)$ and to identify the factors that were associated with efficacy and safety in ICS/LABA/LAMA combination therapy with regard to primary end-points (by anchoring the efficacy and safety with comparators LABA/LAMA combination therapy or single long-acting bronchodilator therapy) [21]. The quality of the evidence was assessed for primary end-points in agreement with the Grading of Recommendations Assessment, Development, and Evaluation (GRADE) system [22]. Detailed methods used to assess the quality of RCTs and the risk of bias are reported in the supplementary material. The OpenMetaAnalyst [23] and GeMTC [24] software was used to perform the meta-analysis, GraphPad Prism (GraphPad Software, La jolla, CA, USA) was used to graph the data and GRADEpro GDT [22] was used to assess the quality of the evidence. Statistical significance was assessed for $\mathrm{p}<0.05$ and moderate to high levels of heterogeneity were considered for $\mathrm{I}^{2}>50 \%$.

\section{Data extraction}

Data from included RCTs were extracted and checked for study characteristics and duration, disease characteristics, age, gender, smoking habit, lung function, health-related quality of life (HRQoL), AECOPD, blood eosinophils, safety profile and Jadad score. Due to the complexity of this meta-analysis, data have been extracted in agreement with Data Extraction for Complex Meta-analysis (DECiMAL) recommendations [25]. When needed, mean and standard deviation have been estimated from the median, range and the sample size as previously described [26].

\section{End-points}

The primary end-points of this meta-analysis were the impact of ICS/LABA/LAMA combination therapy on the risk of moderate or severe AECOPD, the change from baseline in trough forced expiratory volume in $1 \mathrm{~s}\left(\mathrm{FEV}_{1}\right)$ and the risk of pneumonia, compared to LABA/LAMA combination therapy and single long-acting bronchodilator therapy.

The secondary end-points were the impact of ICS/LABA/LAMA combination therapy on the change from baseline in St George's Respiratory Questionnaire (SGRQ) score and the risk of serious adverse events (SAEs), compared to LABA/LAMA combination therapy and single long-acting bronchodilator therapy.

\section{Results \\ Study characteristics}

Data obtained from 16751 COPD patients (57.3\% treated with ICS/LABA/LAMA combination therapy, $28.4 \%$ treated with LABA/LAMA combination therapy and $14.3 \%$ treated with single long-acting bronchodilator therapy) were selected from 14 studies [27-40] published between 2007 and 2018. The relevant studies and patient characteristics are described in supplementary table S2 and supplementary figure S2 shows the network across the treatments involved in the Bayesian analysis.

All the RCTs subjected to meta-analysis were published as full-text papers and all but one [30] had a Jadad score of three or more [27-29, 31-40]. The length of treatment ranged from 2 weeks to 52 weeks.

\section{Meta-analysis}

Primary end-points

The network meta-analysis indicated that ICS/LABA/LAMA combination therapy significantly $(\mathrm{p}<0.001)$ reduced the risk of moderate or severe AECOPD compared to LABA/LAMA combination therapy (relative effect $0.70,95 \%$ CrI $0.53-0.94$ ) and single long-acting bronchodilator therapy (relative effect 0.62, 95\% CrI 
0.48-0.80). ICS/LABA/LAMA combination therapy also significantly $(\mathrm{p}<0.001)$ improved trough FEV 1 from baseline compared to LABA/LAMA combination therapy (relative effect $37.94 \mathrm{~mL}$, 95\% CrI 18.83 53.89) and single long-acting bronchodilator therapy (relative effect $68.82 \mathrm{~mL}, 95 \%$ CrI 56.95-82.48). No significant difference $(p>0.05)$ was found for the risk of pneumonia when comparing ICS/LABA/ LAMA combination therapy with LABA/LAMA combination therapy (relative effect 1.36, 95\% CrI 0.842.00) and single long-acting bronchodilator therapy (relative effect 1.31, 95\% CrI 0.76-2.32).

The SUCRA analysis indicated that ICS/LABA/LAMA combination therapy was the most effective treatment in reducing the risk of moderate or severe AECOPD and increasing trough FEV1, followed by LABA/LAMA combination therapy and single long-acting bronchodilator therapy. Conversely, the risk of pneumonia was lower with LABA/LAMA combination therapy and single long-acting bronchodilator therapy than with ICS/LABA/LAMA combination therapy. Detailed results of the SUCRA analysis and the ranking of the best therapy are reported in table 1. The WA of efficacy and safety resulting from SUCRA analysis provided the following ranking: ICS/LABA/LAMA combination therapy (WA 0.56 ) $\simeq$ LABA/ LAMA combination therapy (WA 0.59) >> single long-acting bronchodilator therapy (WA 0.38), where a higher WA indicates a better efficacy/safety profile.

The results of the pairwise meta-analysis performed on the primary end-points overall confirmed those obtained from the network meta-analysis. Detailed results of pairwise meta-analysis are shown in figure 1.

For the end-point of severe AECOPD, our analysis indicated that ICS/LABA/LAMA combination therapy was significantly $(\mathrm{p}<0.001)$ more effective than LABA/LAMA combination therapy (relative risk $0.78,95 \%$ CI $0.69-0.89 ; \mathrm{I}^{2}=81 \%$ ) or single long-acting bronchodilator therapy (relative risk $0.59,95 \%$ CI $0.42-0.82$; $\mathrm{I}^{2}=82 \%$ ) (supplementary figure S3). The meta-analysis showed that the protective effect of ICS/LABA/ LAMA combination therapy versus LABA/LAMA combination therapy for the risk of moderate or severe AECOPD was greater in patients with higher blood eosinophil counts, ranging from a relative risk of 0.57 (95\% CI $0.48-0.68)$ for counts of $\geqslant 400$ cells $\mu \mathrm{L}^{-1}$ to a relative risk of 0.70 (95\% CI $0.62-0.80$ ) for counts of $\geqslant 150$ cells $\mu \mathrm{L}^{-1}$ (figure $2 \mathrm{a}$ ). The overall meta-regression analysis indicated that the blood eosinophil count was a significant effect modifier of ICS/LABA/LAMA combination therapy in preventing the risk of moderate or severe AECOPD (coefficient $-0.001, \mathrm{p}<0.05$; figure $2 \mathrm{~b}$ ).

The sensitivity analysis indicated that the IMPACT and WISDOM studies [27, 32] represented the main source of heterogeneity with respect to the effect of ICS/LABA/LAMA combination therapy versus LABA/ LAMA combination therapy for the risk of moderate or severe AECOPD. Excluding the results of these RCTs $[27,32]$ from the meta-analysis completely abolished heterogeneity (relative risk $0.87,95 \%$ CI 0.82 $0.92 ; \mathrm{I}^{2}=0 \%$ ). The sensitivity analysis performed by removing the studies of WeLTE et al. [36] and LEE et al. [30] reduced heterogeneity $(\mathrm{p}=0.38$ ) when comparing ICS/LABA/LAMA combination therapy versus single long-acting bronchodilator therapy with regard to the impact on AECOPD (relative risk 0.83, 95\% CI $\left.0.78-0.88 ; \mathrm{I}^{2}=5 \%\right)$. Concerning the effect of ICS/LABA/LAMA combination therapy versus single long-acting bronchodilator therapy on the change from baseline in trough FEV1, deleting the studies of SING et al. [37], SAITO et al. [31] and HANANIA et al. [35] indicated that these RCTs introduced heterogeneity in the meta-analysis (sensitivity analysis: mean difference $+66.21 \mathrm{~mL}, 95 \%$ CI $58.13-74.29$; $\left.\mathrm{I}^{2}=17 \%\right)$. Detailed results of the sensitivity analysis are reported in supplementary figures S4a-S4c.

TABLE 1 Probability of best therapy and SUCRA values for ICS/LABA/LAMA combination therapy, LABA/LAMA combination therapy and single long-acting bronchodilator therapy in chronic obstructive pulmonary disease (COPD) patients

Treatment $\quad$ Probability of being the best therapy \%

\begin{tabular}{ccc}
\hline Risk of & $\begin{array}{c}\text { Change from } \\
\text { baseline in FEV } 1\end{array}$ & $\begin{array}{c}\text { Risk of } \\
\text { pneumonia }\end{array}$
\end{tabular}

Specific SUCRA values

\begin{tabular}{ccc}
\hline Risk of & $\begin{array}{c}\text { Change from } \\
\text { baseline in FEV } 1\end{array}$ & $\begin{array}{c}\text { Risk of } \\
\text { pneumonia }\end{array}$
\end{tabular}

Overall SUCRA

WA of efficacy/

safety

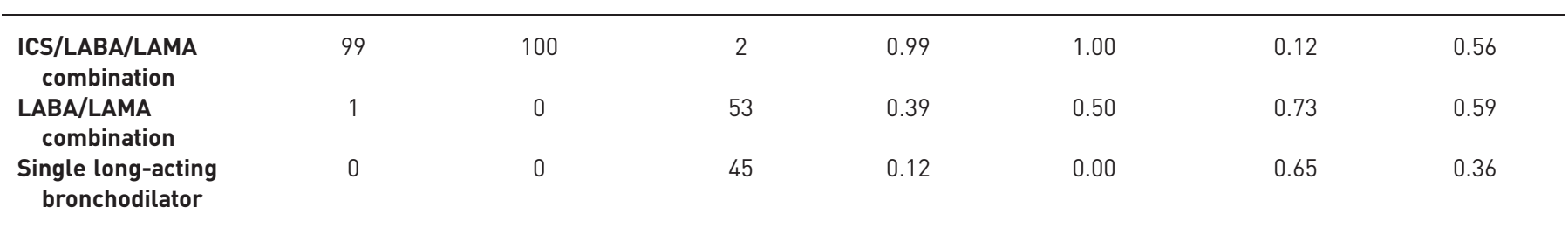

SUCRA: surface under the cumulative ranking curve; ICS: inhaled corticosteroids; LABA: long-acting $\beta_{2}$-agonist; LAMA: long-acting muscarinic receptor antagonist; AECOPD: acute exacerbation of COPD; FEV1: forced expiratory volume in $1 \mathrm{~s}$; WA: weighted average. 
a)

IMPACT (FF/UMEC/NI versus UMEC/NI) 2018 TRIBUTE (BDP/FOR/GLY versus GLY/IND) 2018 OPTIMAL (FP/SAL+TIO versus SAL+TIO) 2007 SUNSET (FP/SAL+TIO versus GLY/IND) 2018 WISDOM (FP/SAL+TIO versus SAL+TIO) 2014

Overall $\left(1^{2}=98 \% ; p<0.01\right)$
Estimate $195 \%$ Cl) $0.75(0.73-0.77)$ $0.85(0.77-0.93)$ $0.85(0.76-0.94)$ $0.92(0.82-1.04)$ $0.96(0.94-0.98)$

$0.86(0.75-0.99)$ 0.4 $\begin{aligned} \text { Favours } & \text { Favours } \\ \text { ICS/LABA/LAMA combination } & \text { LABA/LAMA combination }\end{aligned}$

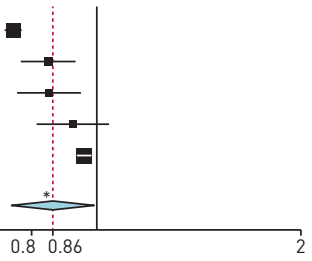

Relative risk (AECOPD) btu

CLIMB (BUD/FOR+TIO versus TIO) 2009 Lee (BUD/FOR+TIO versus TIO) 2016 TRINITY (BDP/FOR+TIO versus TIO) 2017 RINITY (BDP/FOR/GLY versus TIO) 2017 Hanania (FP/SAL+TIO versus TIO) 2011 Jung (FP/SAL+TIO versus TIO) 2012 OPTIMAL (FP/SAL+TIO versus TIO) 2007 Overall $\left(1^{2}=80 \% ; p<0.01\right)$ $\begin{array}{ccll}\text { Eavours } & \text { Favours } & \text { d) } \\ \text { Estimate } 195 \% \mathrm{Cl} & \text { LABA/LAMA combination } & \text { ICS/LABA/LAMA combination } & \text { Studies }\end{array}$ $54.00(39.85-68.15)$ $43.00(16.65-69.35)$ $26.00(-4.99-56.99)$ Studies

IMPACT (FF/UMEC/VI versus UMEC/VII 2018 WISDOM (FP/SAL+TIO versus SAL+TIO) 2014 SUNSET (FP/SAL+TIO versus GLY/ND) 2018 TRIBUTE (BDP/FOR/GLY versus GLY/IND) 20 WISDOM (FP/SAL+TIO versus SAL+TIO) 2007

Overall $\left(\left.\right|^{2}=45 \% ; p=0.13\right)$ $18.00(-86.95-122.95)$ $38.05(22.06-54.04)$

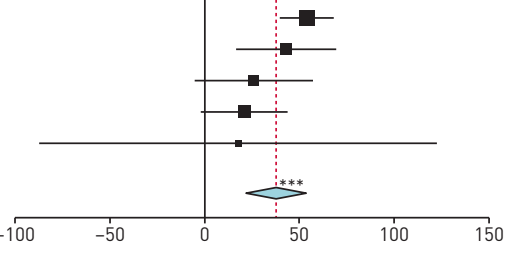

Mean difference (change from baseline in FEV. Saito (FP/SAL+TIO versus TIO) 2015 Hanania (FP/SAL+TIO versus TIO) 2011 Hoshino (FP/SAL+TIO versus TIO) 2013 CLIMB (BUD/FOR+TIO versus TIO) 2009 TRINITY (BDP/FOR+TIO versus TIO) 2017 TRINITY (BDP/FOR/GLY versus TIO) 2017 Hoshino (FP/SAL+TIO versus SAL) 2013 OPTIMAL (FP/SAL+TIO versus TIO) 2007 Lee (BUD/FOR+TIO versus TIO) 2016 Jung (FP/SAL+TIO versus TIO) 2012 Cazzola (FP/SAL+TIO versus TIO) 2007 Dverall ||$^{2}=50 \%$; $\mathrm{p}=0.021$

studies

IMPACT (FF/UMEC/NI versus UMEC/NI) 2018 SUNSET (FP/SAL+TIO versus GLY/IND) 2018 WISDOM (FP/SAL+TIO versus SAL+TIO) 2014 TRIBUTE (BDP/FOR/GLY versus GLY/IND) 2018 OPTIMAL (FP/SAL+TIO versus SAL+TIO) 2007 Overall $\left(I^{2}=47 \% ; \mathrm{p}=0.11\right)$
Estimate $(95 \% \mathrm{Cl})$ $1.71(1.38-2.11)$ $1.50(0.54-4.18)$ $1.06(0.77-1.46)$ $1.04(0.62-1.75)$ $1.02(0.06-16.16)$

$1.31(0.97-1.76)$

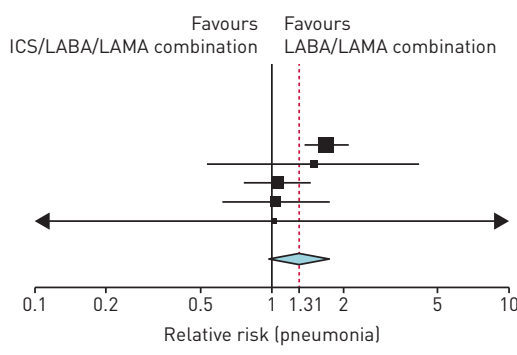

Hanania (FP/SAL+TIO versus TIO) 2011 OPTIMAL (FP/SAL+TIO versus TIO) 2007 TRINITY (BDP/FOR/GLY versus TIO) 2017 TRINITY (BDP/FOR+TIO versus TIO) 2017 Jung (FP/SAL+TIO versus TIO) 2012 CLIMB (BUD/FOR+TIO versus TIO) 2009 Saito (FP/SAL+TIO versus TIO) 2015 Cazzola (FP/SAL+TIO versus TIO) 2007 Lee (BUD/FOR+TIO versus TIO) 2016

Overall $(12=0 \% ; p=0.95)$
Estimate $195 \% \mathrm{Cl})$ $0.38(0.27-0.53)$ $0.59(0.44-0.80)$ $0.79(0.71-0.88$ $0.81(0.74-0.88)$ $0.85(0.52-1.37)$ $0.90(0.61-1.33)$

$0.74(0.64-0.86)$

Favours Favours single
ICS/LABA/LAMA combination

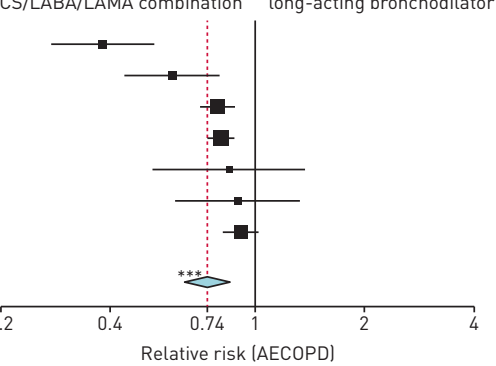

$\begin{array}{rll}\text { Favours single } & \text { Favours } \\ \text { Estimate }(95 \% \mathrm{CI}) \text { long-acting bronchodilator } & \text { ICS/LABA/LAMA combination }\end{array}$ $211.00(109.13-312.87)$ $128.00(55.87-200.13)$ $117.00(58.47-175.53)$ $79.00(69.28-88.72)$ $65.00(36.75-93.25)$ $64.00(38.51-89.49)$ $61.00(35.50-86.50)$ $61.00(48.06-73.94)$ $59.00(-36.76-154.76)$ $54.00(26.93-81.07)$ $52.00(-12.39-116.39)$ $45.00(11.69-78.31)$

$68.48(56.53-80.43)$

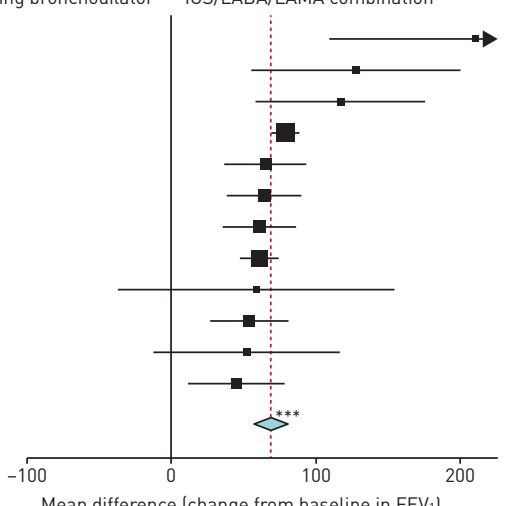

Estimate $(95 \% \mathrm{Cl})$ $4.89(0.24-101.01)$ $3.23(0.13-78.56)$ $1.47(0.83-2.62)$ $1.27(0.62-2.59)$ $1.04(0.15-7.32)$ $1.00(0.20-4.93)$ $1.00(0.02-49.44)$ $0.90(0.02-43.81)$ $0.50(0.09-2.71)$

$1.30(0.88-1.94)$
Favours Favours single

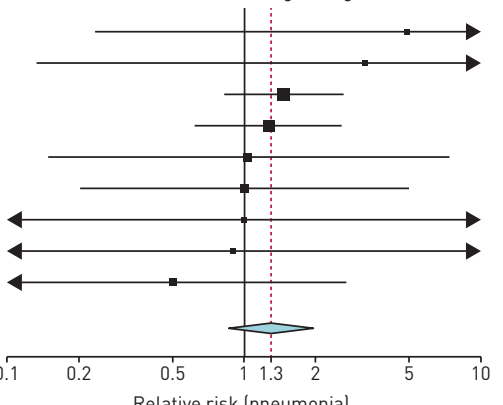

FIGURE 1 Primary end-points: forest plots of the impact of inhaled corticosteroid (ICS)/long-acting $\beta_{2}$-agonist (LABA)/long-acting muscarinic receptor antagonist (LAMA) combination therapy versus $a, c$ and e) LABA/LAMA combination therapy and b, $d$ and f) single long-acting bronchodilator therapy, a and b) on the risk of moderate or severe acute exacerbation of chronic obstructive pulmonary disease (AECOPD), $\mathrm{c}$ and d) on change from baseline in forced expiratory volume in $1 \mathrm{~s}$ (FEV1) and e and f) on risk of pneumonia in chronic obstructive pulmonary disease patients. The studies have been sorted by the extent of effect. FF: fluticasone furoate; UMEC: umeclidinium bromide; VI: vilanterol; BDP: beclometasone dipropionate; FOR: formoterol fumarate; GLY: glycopyrronium bromide; IND: indacaterol; FP: fluticasone propionate; SAL: salmeterol; TIO: tiotropium bromide; BUD: budesonide. *: p<0.05 versus comparators; ${ }^{* * *}: p<0.001$ versus comparators. 
a)

Cumulative studies

WISDOM (FP/SAL+TIO versus SAL+TIO; eosinophils $\geqslant 400$ cells $\mu \mathrm{L}^{-1}$ ) + WISDOM (FP/SAL+TIO versus SAL+TIO; eosinophils $\geqslant 300$ cells $\mu L^{-1}$ ) +SUNSET (FP/SAL+TIO versus GLY/IND; eosinophils $\geqslant 300$ cells. $\mu \mathrm{L}^{-1}$ ) + TRIBUTE (BDP/FOR/GLY versus GLY/IND; eosinophils $\geqslant 200$ cells. $\mu L^{-1}$ ) + WISDOM (FP/SAL+TIO versus SAL+TIO; eosinophils $\geqslant 150$ cells. $\mu L^{-1}$ ) + IMPACT (FF/UMEC/VI versus UMEC/VI; eosinophils $\geqslant 150$ cells. $\mu \mathrm{L}^{-1}$ )

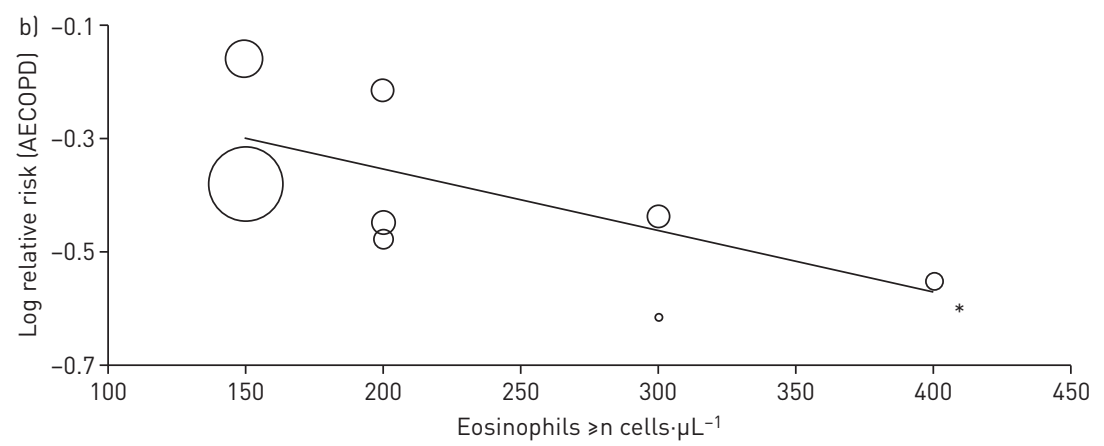

Cumulative estimate (95\% CI)

$0.57(0.48-0.68)$ $0.61(0.55-0.69)$ $0.61(0.55-0.68)$ $0.66(0.55-0.79)$ $0.70(0.59-0.83)$ $0.70(0.62-0.80)$

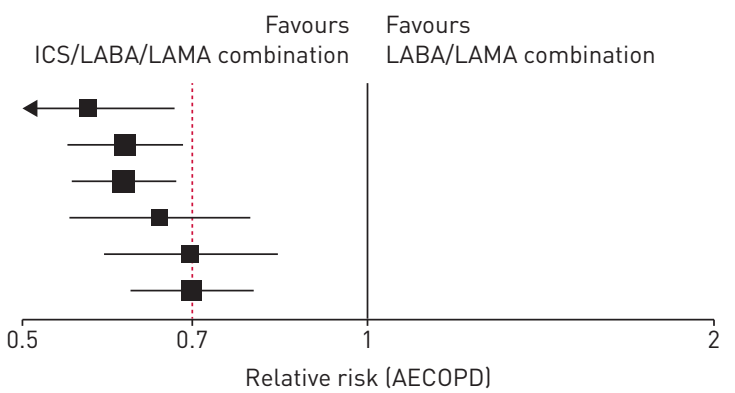

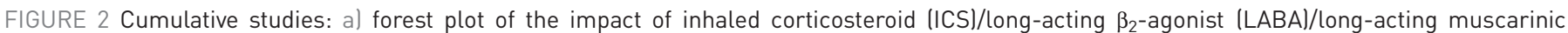
receptor antagonist (LAMA) combination therapy versus LABA/LAMA combination therapy on the risk of moderate or severe acute exacerbation of chronic obstructive pulmonary disease (AECOPD) in chronic obstructive pulmonary disease patients in agreement with the blood eosinophil counts, and b) meta-regression analysis of the overall impact of ICS/LABA/LAMA combination therapy versus long-acting bronchodilators against the risk of moderate or severe AECOPD in agreement with the blood eosinophil counts. FP: fluticasone propionate; SAL: salmeterol; TIO: tiotropium bromide; GLY: glycopyrronium bromide; IND: indacaterol; BDP: beclometasone dipropionate; FOR: formoterol fumarate; FF: fluticasone furoate; UMEC: umeclidinium bromide; VI: vilanterol. *: $p<0.05$ for the blood eosinophil counts covariate.

Secondary end-points

ICS/LABA/LAMA combination therapy reduced the change in SGRQ score versus long-acting bronchodilators (overall effect estimate: mean difference -3.22 , 95\% CI $-4.44--2.00 ; \mathrm{I}^{2}=85 \%$ ), although the effect was significantly $(\mathrm{p}<0.05)$ greater versus single long-acting bronchodilator therapy (mean difference $-4.20,95 \% \mathrm{CI}-6.03--2.37 ; \mathrm{I}^{2}=86 \%$ ) than versus LABA/LAMA combination therapy (mean difference $-1.63,95 \% \mathrm{CI}-2.23--1.04 ; \mathrm{I}^{2}=0 \%$ ) (figures $3 \mathrm{a}$ and $3 \mathrm{~b}$ ). The impact of triple combination therapy on the risk of SAEs is shown in figures $3 \mathrm{c}$ and $3 \mathrm{~d}$ and further details are reported in the supplementary material.

\section{Number need to treat and number needed to harm analysis}

The person-based NNT per year concerning the prevention of AECOPD was 38.17 for ICS/LABA/LAMA combination therapy versus LABA/LAMA combination therapy and 21.43 versus single long-acting bronchodilator therapy. The person-based NNT per year of ICS/LABA/LAMA combination therapy versus LABA/LAMA combination therapy was significantly $(\mathrm{p}<0.05)$ lower in patients with $\geqslant 300$ cells $\mu \mathrm{L}^{-1}$ (NNT value: 8.58 ) than in those with $<300$ cells. $\mu \mathrm{L}^{-1}$ (NNT value: 46.28 ). Further details (and 95\% CI values) of person-based NNT analysis at different time points are shown in table 2 and indicate that the patients that were most likely to benefit from ICS/LABA/LAMA combination therapy where those with higher blood eosinophil counts. Detailed NNT values concerning the effect of triple combination therapy on trough FEV1 are reported in the supplementary material.

Considering pneumonia as the outcome, the person-based NNH of ICS/LABA/LAMA combination therapy versus LABA/LAMA combination therapy was 195.34 (95\% CI $85.06-\infty)$. In the subset analysis performed by considering the only RCT that included fluticasone furoate (FF) in the triple combination [27], the person-based NNH for ICS/LABA/LAMA combination therapy diminished to 33.89 (95\% CI 30.69-37.84) versus LABA/LAMA combination therapy.

\section{Meta-regression analysis}

Along with blood eosinophil count, the overall meta-regression analysis indicated that Jadad score (coefficient: $-0.083, \mathrm{p}<0.05$ ) and study duration (coefficient: $-0.006, \mathrm{p}<0.05$ ) were significant effect modifiers of ICS/LABA/LAMA combination therapy for the analysis of moderate or severe AECOPD. No significant effect modifiers were found for trough FEV1. The meta-regression analysis indicated that the 
a) Studies

OPTIMAL (FP/SAL+TIO versus SAL+TIO) 2007 IMPACT (FF/UMEC/NI versus UMEC/NI) 2018 TRIBUTE (BDP/FOR/GLY versus GLY/IND) 2018 WISDOM (FP/SAL+TIO versus SAL+TIO) 2014

Overall $\left(l^{2}=0 \% ; \mathrm{p}=0.85\right)$

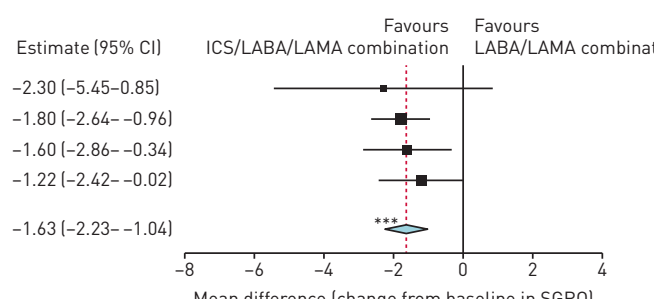

Mean difference Ichange trom baseline in ScRol

c)

Studies

Favours Favours

TRIBUTE (BDP/FOR/GLY versus GLY/IND) $2018 \quad 0.90(0.72-1.14)$

IMPACT (FF/UMEC/NI versus UMEC/NI) $2018 \quad 0.96(0.87-1.06)$

WISDOM (FP/SAL+TIO versus SAL+TIO) $2007 \quad 0.97(0.84-1.12)$

OPTIMAL (FP/SAL+TIO versus SAL+TIO) $2007 \quad 1.02(0.42-2.50)$

SUNSET (FP/SAL+TIO versUS GLY/IND) $2018 \quad 1.06(0.67-1.70)$

Overall $\left(\left.\right|^{2}=0 \% ; \mathrm{p}=0.97\right.$

$0.96(0.89-1.03)$

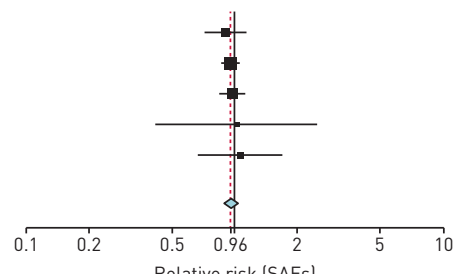

Relative risk (SAEs)
Hoshino (FP/SAL+TIO versus SAL) 2013 Hoshino (FP/SAL+TIO versus TIO) 2013 Lee (BUD/FOR+TIO versus TIO) 2016 OPTIMAL (FP/SAL+TIO versus TIO) 2007 TRINITY (BDP/FOR+TIO versus TIO) 2017 TRINITY (BDP/FOR/GLY versus TIO) 2017

Overall $(1=88 \% ; p<0.01)$

d)

Studies

Hanania (FP/SAL+TIO versus TIO) 201 Lee (BUD/FOR+TIO versus TIO) 2016 CLIMB (BUD/FOR+TIO versus TIO) 2009 TRINITY (BDP/FOR+TIO versus TIO) 2017 TRINITY (BDP/FOR/GLY versus TIO) 2017 Cazzola (FP/SAL+TIO versus TIO) 2007 OPTIMAL IFP/SAL+TIO versus TIO) 2007 Singh (FP/SAL+TIO versus TIO) 2008 Jung (FP/SAL+TIO versus TIO) 2012 Saito (FP/SAL+TIO versus TIO) 2015

Overall $\left(I^{2}=0 \% ; p=0.72\right)$
Estimate $195 \% \mathrm{CIl}$

$-7.40(-9.16--5.64)$ $-6.20(-7.76--4.64)$ $-5.20(-8.31--2.09)$ $-4.10(-7.19--1.01)$ $-3.14(-4.57--1.71)$ $-1.57(-2.74--0.40)$ $-4.55(-6.62--2.49)$ -8

Estimate $195 \% \mathrm{Cll}$ $0.53(0.22-1.29)$ $0.58(0.31-1.10)$ $0.63(0.29-1.36)$ $0.83(0.64-1.08)$ $0.85(0.69-1.05)$ $0.90(0.02-43.81)$ $0.97(0.40-2.32)$ $0.97(0.40-2.32]$ $1.00(0.27-3.65)$ $1.30(0.69-2.44)$ $5.00(0.25-101.58$ $0.84(0.72-0.97)$

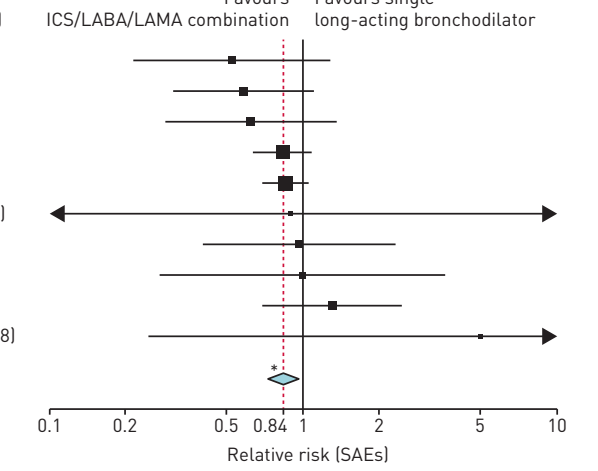

FIGURE 3 Secondary end-points: forest plots of the impact of inhaled corticosteroid (ICS)/long-acting $\beta_{2}$-agonist (LABA)/long-acting muscarinic receptor antagonist (LAMA) combination therapy versus $a$ and c) LABA/LAMA combination therapy and b and d) single long-acting bronchodilator therapy, a and b) on the change from baseline in St George's Respiratory Questionnaire (SGRQ) and $c$ and d) on the risk of serious adverse events (SAEs) in chronic obstructive pulmonary disease patients. The studies were sorted by the extent of effect. FP: fluticasone propionate; SAL: salmeterol; TIO: tiotropium bromide; FF: fluticasone furoate; UMEC: umeclidinium bromide; VI: vilanterol; BDP: beclometasone dipropionate; FOR: formoterol fumarate; GLY: glycopyrronium bromide; IND: indacaterol; BUD: budesonide. *: $p<0.05$ versus comparators; ***: $p<0.001$ versus comparators. 
TABLE 2 Person-based number needed to treat (NNT) at various time points concerning the prevention of acute exacerbation of COPD (AECOPD) and subset analysis based on the blood eosinophil counts in chronic obstructive pulmonary disease (COPD) patients treated with ICS/LABA/LAMA combination therapy versus LABA/LAMA combination therapy or single long-acting bronchodilator therapy

\begin{tabular}{|c|c|c|c|c|c|c|c|c|}
\hline \multirow[t]{3}{*}{$\begin{array}{l}\text { Duration of } \\
\text { treatment }\end{array}$} & \multicolumn{5}{|c|}{$\begin{array}{l}\text { ICS/LABA/LAMA combination therapy versus LABA/LAMA } \\
\text { combination therapy }\end{array}$} & \multicolumn{3}{|c|}{$\begin{array}{l}\text { ICS/LABA/LAMA combination therapy versus } \\
\text { single long-acting bronchodilator therapy" }\end{array}$} \\
\hline & \multicolumn{2}{|c|}{ Overall rates } & \multirow[t]{2}{*}{ Overall NNT ๆ } & \multicolumn{2}{|c|}{$\begin{array}{l}\text { NNT in agreement with } \\
\text { blood eosinophil count }\end{array}$} & \multicolumn{2}{|c|}{ Overall rates } & \multirow[t]{2}{*}{ Overall NNT } \\
\hline & $\begin{array}{l}\text { ICS/LABA/ } \\
\text { LAMA } \\
\text { combination } \\
\text { arm }\end{array}$ & $\begin{array}{c}\text { LABA/LAMA } \\
\text { combination } \\
\text { arm }\end{array}$ & & $\begin{array}{l}<300 \\
\text { cells· } \mu \mathrm{L}^{-1}\end{array}$ & $\begin{array}{l}\geqslant 300 \\
\text { cells } \mu \mathrm{L}^{-1}\end{array}$ & $\begin{array}{c}\text { ICS/LABA/ } \\
\text { LAMA } \\
\text { combination } \\
\text { arm }\end{array}$ & $\begin{array}{c}\text { Single } \\
\text { long-acting } \\
\text { bronchodilator } \\
\text { arm }\end{array}$ & \\
\hline 3 months & 0.32 & 0.26 & $\begin{array}{c}19.99 \\
(14.72-35.72)\end{array}$ & $\begin{array}{c}61.00 \\
(15.26-\infty)\end{array}$ & $\begin{array}{c}7.33 \\
(4.50-19.77)\end{array}$ & 0.17 & 0.15 & $\begin{array}{c}15.08 \\
(12.23-27.17)\end{array}$ \\
\hline 6 months & 0.41 & 0.37 & $\begin{array}{c}23.02 \\
(12.70-103.86)\end{array}$ & $\begin{array}{c}61.00 \\
(12.26-\infty)\end{array}$ & $\begin{array}{c}10.76 \\
(4.78-35.84)\end{array}$ & 0.26 & 0.21 & $\begin{array}{c}23.88 \\
(12.75-49.90)\end{array}$ \\
\hline 12 months & 0.50 & 0.47 & $\begin{array}{c}38.17 \\
(11.75-168.41)\end{array}$ & $\begin{array}{c}46.28 \\
(21.00-\infty)\end{array}$ & $\begin{array}{c}8.58 \\
(5.93-15.54)\end{array}$ & 0.37 & 0.32 & $\begin{array}{c}21.43 \\
(10.95-316.78)\end{array}$ \\
\hline
\end{tabular}

Data are presented as $\mathrm{n}(95 \% \mathrm{Cl})$ unless otherwise stated. All data are calculated as weighted averages. ICS: inhaled corticosteroids; LABA: long-acting $\beta_{2}$-agonist; LAMA: long-acting muscarinic receptor antagonist. \#: data on blood eosinophil count concerning ICS/LABA/LAMA combination therapy versus single long-acting bronchodilator therapy are not reported since they were not available in the primary publications; " : the overall NNT was calculated by using the weighted rates of the arms reported in each study.

presence of FF in the ICS/LABA/LAMA combination led to significant effect modification with respect to the impact on the risk of pneumonia (coefficient: 0.46, $\mathrm{p}<0.01$ ). In addition, FEV1 values at baseline (coefficient: $0.03, \mathrm{p}<0.05$ ) and gender (male/female: $-0.03, \mathrm{p}<0.01$ ) were effect modifiers for the risk of pneumonia; however, study duration and Jadad score did not significantly $(\mathrm{p}>0.05)$ influence the impact of ICS/LABA/LAMA combination therapy on the risk of pneumonia.

\section{Bias and quality of evidence}

Substantial levels of heterogeneity resulted for ICS/LABA/LAMA combination therapy versus LABA/ LAMA combination therapy and single long-acting bronchodilator therapy with regard to the risk of moderate or severe AECOPD $(\mathrm{p}<0.001)$. Heterogeneity also resulted for ICS/LABA/LAMA combination therapy versus LABA/LAMA combination therapy versus single long-acting bronchodilator therapy with respect to the change from baseline in $\mathrm{FEV}_{1}(\mathrm{p}<0.05)$.

Detailed results concerning the analysis of bias and quality of evidence are reported in the supplementary material as supplementary figure S5 and supplementary table S3.

\section{Discussion}

The main findings of the present meta-analysis indicated that ICS/LABA/LAMA combination therapy was significantly more effective than both LABA/LAMA combination therapy and single long-acting bronchodilator therapy in reducing the risk of moderate or severe AECOPD and improving lung function. While $~ 38$ patients had to be treated for 1 year with an ICS/LABA/LAMA combination to prevent one moderate or severe AECOPD compared to a LABA/LAMA combination, the NNT was 21 when compared to single long-acting bronchodilator therapy. The protective effect of ICS/LABA/LAMA combination therapy compared to LABA/LAMA combination therapy, relative to the risk of moderate or severe AECOPD, became greater in patients with higher blood eosinophil counts. In patients with blood eosinophil counts $\geqslant 300$ cells. $\mu \mathrm{L}^{-1}$, the NNT for ICS/LABA/LAMA combination therapy versus LABA/ LAMA combination therapy, to prevent one AECOPD in 1 year, dropped to $\sim 9$ patients. In those with blood eosinophil counts $<300$ cells $\mu \mathrm{L}^{-1}$, the NNT was $\sim 46$.

No significant differences were detected with respect to the risk of pneumonia between triple combination therapy and comparators. However, the subset analysis of the RCT that included FF in the triple combination therapy [27] showed that one out of $\sim 34$ patients treated for 1 year with a FF/umeclidinium bromide (UMEC)/vilanterol (VI) combination experienced pneumonia when compared to an UMEC/VI combination. Unexpectedly, female COPD patients seemed to be at higher risk of pneumonia and the risk of pneumonia was greater when the value of FEV1 was high at enrolment. 
These findings seem to support the current recommendations of the Global Initiative for Chronic Obstructive Lung Disease (GOLD) management strategy for COPD, which suggest the use of triple therapy in patients who have clinically significant symptoms and are at increased risk for frequent or severe exacerbations (GOLD group D) [6].

Nevertheless, we must highlight that the large influence of the IMPACT study [27] in the meta-analysis, as demonstrated by the significant asymmetry of the funnel plot, led to a potentially biased effect estimate. The source of bias in the IMPACT study [27] is likely the enrolment of a significant percentage of patients with a history of asthma [41], such that $18 \%$ of the patients had significant bronchodilator reversibility (post-salbutamol increase in $\mathrm{FEV}_{1}: \geqslant 12 \%$ and $\geqslant 200 \mathrm{~mL}$ ). However, triple therapy showed statistically significant and clinically relevant improvements on a range of important outcomes compared with LAMA/ LABA combination therapy regardless of baseline reversibility [42].

The evidence generated by this systematic review and quantitative synthesis on the available clinical evidence can help to fill, at least in part, those gaps in knowledge with regards to ICS/LABA/LAMA combination therapy and its efficacy versus LABA/LAMA combination therapy. Patients on single long-acting bronchodilator therapy or LABA/LAMA combination therapy, who still experience AECOPD and have blood eosinophil counts $\geqslant 300$ cells $\mu \mathrm{L}^{-1}$, may benefit from triple combination therapy. Nevertheless, we must emphasise that while meta-analyses have evolved as a technique to be useful for summarising a large number of RCTs and for resolving discrepancies that are raised by those trials, they deal with populations and not with single individuals. Thus, clinicians must use clinical judgement when applying the conclusions of this and other studies to the individual patient.

Author contributions: P. Rogliani provided the funding for this article. M. Cazzola and L. Calzetta completed the literature search and assessed the eligibility of studies for inclusion. All were directly involved in the acquisition of data for the article. L. Calzetta designed the statistical analyses in consultation with M. Cazzola, P. Rogliani and M.G. Matera. Statistical analyses were performed by L. Calzetta and M. Cazzola. L. Calzetta wrote the first draft of the article, in consultation with P. Rogliani and M.G. Matera for data interpretation. All authors revised the article critically for important intellectual content, gave final approval of the version to be published and agreed to be accountable for all aspects of the article in ensuring that questions related to its accuracy or integrity were appropriately investigated and resolved. L. Calzetta is the guarantor of this review and meta-analysis.

Conflict of interest: M. Cazzola has participated as a faculty member and advisor in scientific meetings and courses under the sponsorship of Almirall, AstraZeneca, Biofutura, Boehringer Ingelheim, Chiesi Farmaceutici, GlaxoSmithKline, Menarini Group, Lallemand, Mundipharma, Novartis, Pfizer, Recipharm, Verona Pharma and Zambon, and is or has been a consultant to ABC Farmaceutici, AstraZeneca, Chiesi Farmaceutici, Recipharm, Lallemand, Novartis, Ockham Biotech, Verona Pharma and Zambon. His department was funded by Almirall, Boehringer Ingelheim, Novartis and Zambon. P. Rogliani participated as a lecturer and advisor in scientific meetings and courses under the sponsorship of Almirall, AstraZeneca, Biofutura, Boehringer Ingelheim, Chiesi Farmaceutici, GlaxoSmithKline, Menarini Group, Mundipharma and Novartis. Her department was funded by Almirall, Boehringer Ingelheim, Chiesi Farmaceutici, Novartis and Zambon. L. Calzetta has participated as an advisor in scientific meetings under the sponsorship of Boehringer Ingelheim and Novartis, received non-financial support from AstraZeneca, a research grant partially funded by Chiesi Farmaceutici, Boehringer Ingelheim, Novartis and Almirall, and is or has been a consultant to $\mathrm{ABC}$ Farmaceutici, Recipharm, Zambon, Verona Pharma and Ockham Biotech. His department was funded by Almirall, Boehringer Ingelheim, Chiesi Farmaceutici, Novartis and Zambon. M.G. Matera has participated as a lecturer and advisor in scientific meetings and courses under the sponsorship of Almirall, AstraZeneca, Boehringer Ingelheim, Chiesi Farmaceutici, GlaxoSmithKline and Novartis, and has been a consultant to ABC Farmaceutici and Chiesi Farmaceutici. Her department was funded by Novartis.

Support statement: This study was supported by institutional funds (1010107CTBOE16 University of Rome "Tor Vergata"). The funder had no role in study design, data collection, data analysis, data interpretation, or writing of the report. No sponsor had a role in this review and meta-analysis. The corresponding author had full access to all the data in the study and had final responsibility for the decision to submit for publication. Funding information for this article has been deposited with the Crossref Funder Registry.

\section{References}

1 Bettoncelli G, Blasi F, Brusasco V, et al. The clinical and integrated management of COPD. An official document of AIMAR (Interdisciplinary Association for Research in Lung Disease), AIPO (Italian Association of Hospital Pulmonologists), SIMER (Italian Society of Respiratory Medicine), SIMG (Italian Society of General Medicine). Multidiscip Respir Med 2014; 9: 25.

2 Kankaanranta H, Harju T, Kilpelainen M, et al. Diagnosis and pharmacotherapy of stable chronic obstructive pulmonary disease: the Finnish guidelines. Basic Clin Pharmacol Toxicol 2015; 116: 291-307.

3 Zysman M, Chabot F, Devillier P, et al. Pharmacological treatment optimization for stable chronic obstructive pulmonary disease. Proposals from the Société de Pneumologie de Langue Française. Rev Mal Respir 2016; 33: 911-936.

4 Miravitlles M, Soler-Cataluna JJ, Calle M, et al. Spanish guidelines for management of chronic obstructive pulmonary disease (GesEPOC) 2017. Pharmacological treatment of stable phase. Arch Bronconeumol 2017; 53: 324-335.

5 Aisanov Z, Avdeev S, Arkhipov V, et al. Russian guidelines for the management of COPD: algorithm of pharmacologic treatment. Int J Chron Obstruct Pulmon Dis 2018; 13: 183-187. 
6 Vogelmeier CF, Criner GJ, Martinez FJ, et al. Global Strategy for the Diagnosis, Management, and Prevention of Chronic Obstructive Lung Disease 2017 Report: GOLD Executive Summary. Eur Respir J 2017; 49: 1700214.

7 James GD, Donaldson GC, Wedzicha JA, et al. Trends in management and outcomes of COPD patients in primary care, 2000-2009: a retrospective cohort study. NPJ Prim Care Respir Med 2014; 24: 14015.

8 Brusselle G, Price D, Gruffydd-Jones K, et al. The inevitable drift to triple therapy in COPD: an analysis of prescribing pathways in the UK. Int J Chron Obstruct Pulmon Dis 2015; 10: 2207-2217.

9 Simeone JC, Luthra R, Kaila S, et al. Initiation of triple therapy maintenance treatment among patients with COPD in the US. Int J Chron Obstruct Pulmon Dis 2017; 12: 73-83.

10 Moher D, Shamseer L, Clarke M, et al. Preferred reporting items for systematic review and meta-analysis protocols (PRISMA-P) 2015 statement. Syst Rev 2015; 4: 1.

11 Schardt C, Adams MB, Owens T, et al. Utilization of the PICO framework to improve searching PubMed for clinical questions. BMC Med Inform Decis Mak 2007; 7: 16.

12 Rojas-Reyes MX, García Morales OM, Dennis RJ, et al. Combination inhaled steroid and long-acting beta -agonist in addition to tiotropium versus tiotropium or combination alone for chronic obstructive pulmonary disease. Cochrane Database Syst Rev 2016; 6: CD008532.

13 Calverley PMA, Magnussen H, Miravitlles M, et al. Triple therapy in COPD: what we know and what we don't. COPD 2017; 14: 648-662.

14 Singh D, Corradi M, Spinola M, et al. Triple therapy in COPD: new evidence with the extrafine fixed combination of beclomethasone dipropionate, formoterol fumarate, and glycopyrronium bromide. Int J Chron Obstruct Pulmon Dis 2017; 12: 2917-2928.

15 Calzetta L, Rogliani P, Matera MG, et al. A systematic review with meta-analysis of dual bronchodilation with LAMA/LABA for the treatment of stable COPD. Chest 2016; 149: 1181-1196.

16 Cazzola M. Application of number needed to treat (NNT) as a measure of treatment effect in respiratory medicine. Treat Respir Med 2006; 5: 79-84.

17 Aaron SD, Fergusson DA. Exaggeration of treatment benefits using the "event-based" number needed to treat. Can Med Assoc J 2008; 179: 669-671.

18 Suissa S. Number needed to treat in COPD: exacerbations versus pneumonias. Thorax 2013; 68: 540-543.

19 Altman DG, Andersen PK. Calculating the number needed to treat for trials where the outcome is time to an event. BMJ 1999; 319: 1492-1495.

20 Altman DG. Confidence intervals for the number needed to treat. BMJ 1998; 317: 1309-1312.

21 Cazzola M, Rogliani P, Calzetta L, et al. Impact of mucolytic agents on COPD exacerbations: a pair-wise and network meta-analysis. COPD 2017; 14: 552-563.

22 Guyatt G, Oxman AD, Akl EA, et al. GRADE guidelines: 1. Introduction-GRADE evidence profiles and summary of findings tables. J Clin Epidemiol 2011; 64: 383-394.

23 Wallace BC, Dahabreh IJ, Trikalinos TA, et al. Closing the gap between methodologists and end-users: R as a computational back-end. J Stat Softw 2012; 49: 1-15. www.jstatsoft.org/article/view/v049i05

24 van Valkenhoef G, Lu G, de Brock B, et al. Automating network meta-analysis. Res Synth Methods 2012; 3 285-299.

25 Pedder H, Sarri G, Keeney E, et al. Data extraction for complex meta-analysis (DECiMAL) guide. Syst Rev 2016; 5: 212.

26 Hozo SP, Djulbegovic B, Hozo I. Estimating the mean and variance from the median, range, and the size of a sample. BMC Med Res Methodol 2005; 5: 13.

27 Lipson DA, Barnhart F, Brealey N, et al. Once-daily single-inhaler triple versus dual therapy in patients with COPD. N Engl J Med 2018; 378: 1671-1680.

28 Papi A, Vestbo J, Fabbri L, et al. Extrafine inhaled triple therapy versus dual bronchodilator therapy in chronic obstructive pulmonary disease (TRIBUTE): a double-blind, parallel group, randomised controlled trial. Lancet 2018; 391: 1076-1084

29 Vestbo J, Papi A, Corradi M, et al. Single inhaler extrafine triple therapy versus long-acting muscarinic antagonist therapy for chronic obstructive pulmonary disease (TRINITY): a double-blind, parallel group, randomised controlled trial. Lancet 2017; 389: 1919-1929.

30 Lee SD, Xie CM, Yunus F, et al. Efficacy and tolerability of budesonide/formoterol added to tiotropium compared with tiotropium alone in patients with severe or very severe COPD: a randomized, multicentre study in East Asia. Respirology 2016; 21: 119-127.

31 Saito T, Takeda A, Hashimoto K, et al. Triple therapy with salmeterol/fluticasone propionate 50/250 plus tiotropium bromide improve lung function versus individual treatments in moderate-to-severe Japanese COPD patients: a randomized controlled trial - Evaluation of Airway sGaw after treatment with tripLE. Int J Chron Obstruct Pulmon Dis 2015; 10: 2393-2404.

32 Magnussen H, Disse B, Rodriguez-Roisin R, et al. Withdrawal of inhaled glucocorticoids and exacerbations of COPD. N Engl J Med 2014; 371: 1285-1294.

33 Hoshino M, Ohtawa J. Effects of tiotropium and salmeterol/fluticasone propionate on airway wall thickness in chronic obstructive pulmonary disease. Respiration 2013; 86: 280-287.

34 Jung KS, Park HY, Park SY, et al. Comparison of tiotropium plus fluticasone propionate/salmeterol with tiotropium in COPD: a randomized controlled study. Respir Med 2012; 106: 382-389.

35 Hanania NA, Crater GD, Morris AN, et al. Benefits of adding fluticasone propionate/salmeterol to tiotropium in moderate to severe COPD. Respir Med 2012; 106: 91-101.

36 Welte T, Miravitlles M, Hernandez P, et al. Efficacy and tolerability of budesonide/formoterol added to tiotropium in patients with chronic obstructive pulmonary disease. Am J Respir Crit Care Med 2009; 180: 741-750.

37 Singh D, Brooks J, Hagan G, et al. Superiority of "triple" therapy with salmeterol/fluticasone propionate and tiotropium bromide versus individual components in moderate to severe COPD. Thorax 2008; 63: 592-598.

38 Cazzola M, Ando F, Santus P, et al. A pilot study to assess the effects of combining fluticasone propionate/ salmeterol and tiotropium on the airflow obstruction of patients with severe-to-very severe COPD. Pulm Pharmacol Ther 2007; 20: 556-561.

39 Aaron SD, Vandemheen KL, Fergusson D, et al. Tiotropium in combination with placebo, salmeterol, or fluticasone-salmeterol for treatment of chronic obstructive pulmonary disease: a randomized trial. Ann Intern Med 2007; 146: 545-555. 
40 Chapman KR, Hurst JR, Frent SM, et al. Long-term triple therapy de-escalation to indacaterol/glycopyrronium in COPD patients (SUNSET): a randomized, double-blind, triple-dummy clinical trial. Am J Respir Crit Care Med 2018; 198: 329-339.

41 Suissa S, Drazen JM. Making sense of triple inhaled therapy for COPD. N Engl J Med 2018; 378: 1723-1724.

42 Wise R, van der Valk R, Hilton E, et al. Treatment effects of FF/UMEC/VI vs FF/VI and UMEC/VI in reversible and nonreversible COPD patients: analyses of the IMPACT study. Chest 2018; 154: Suppl. 4, 729A-731A. 